\title{
Excitonic Solar Cells: A Review
}

\author{
M. M. Samy ${ }^{1, *}$, M. S. Salem ${ }^{2,3}$ and T. M. Abdolkader ${ }^{1}$ \\ ${ }^{1}$ Department of Basic Engineering Sciences, Banha Faculty of Engineering, Banha University, Egypt \\ ${ }^{2}$ Department of Computer Engineering, College of Computer Science and Engineering, University of Ha'il, KSA \\ ${ }^{3}$ Department of Electrical Communication and Electronics Systems Engineering, Faculty of Engineering, Modern Science \\ and Arts (MSA) University, Cairo, Egypt
}

*Corresponding author: E-mail: menah_samy@yahoo.com, Tel. 00201067387274

Received 17 May 2021

Revised 11 June 2021

Accepted for publication 15 November 2021

Published Online 15 November 2021

\begin{abstract}
Organic solar cells are the latest generation of photovoltaic cells. They contain one or several photoactive materials sandwiched between two electrodes. They can convert sunlight to electrical energy effectively. In this review paper, we present a comprehensive summary of the different organic solar cell (OSC) families. The main aim is to study the comparison between Dye-sensitized "DSSC", Organic, and Hybrid Organic-inorganic "excluding perovskite" solar cells. The performance, materials, theory of operation, and fabrication techniques of each excitonic solar cell type are presented. The first section describes the different types of excitonic solar cells. The second part talks about a comparison between the different related works in literature. The final section explicates the preparation of different materials applied for electrodes. The progress of numerous organic materials which are used as the active layer and their influence on device efficiencies are also illustrated. Concluding, several transparent anode materials are used to fabricate organic solar cells in the presence of an active layer. The obtained research findings indicate that the experimental conditions and the different types of organic solar cells can control the properties of the produced samples.
\end{abstract}

Keywords: Dye-sensitized solar cells; Review; Hybrid organic-inorganic solar cells; Organic solar cells.

\section{Introduction}

Sunlight-based cells are devices that use the light energy of the sun and convert it into electrical energy, which is required for controlling electrical gadgets. The solar cells passed through numerous steps, starting from the simple solar cell, afterward cells based on thin film, and finally the third generation which has a flexible substrate and basic low-cost materials[1]. DSSCs and OSCs are classified as third-generation cells, and recently hybrid organic-inorganic solar cells are classified as fourth-generation cells[2].

Organic solar cells (OSCs) switched to using polymers instead of semiconductors like silicon and gallium arsenide but they are still similar to the fundamental structure of inorganic solar cells (ISC). OSCs have many advantages such as flexibility, lightweight, low cost in material and processing, absence of toxic materials, and being environmentally friendly. So, they are distinguished over ISCs. The band gap energy ranges between 1.0 and $4.0 \mathrm{eV}$.
The difference between ISCs and OSCs is that, the first operates in $\mathrm{p}-\mathrm{n}$ junction semiconductor while the second is based on the concept of donor and acceptor. The efficiency can be improved by optimizing various parameters such as the properties of the material, the thicknesses of the vigorous layer separation between donor and acceptor links, and optical absorption range [3].

DSSCs started by using a chlorophyll zinc oxide $(\mathrm{ZnO})$ electrode in 1972. The efficiency of these devices was poor. Primordially, electric flow can be gotten from photons by infusing the charge of energized color particles into a wide band hole semiconductor. Using a monolayer of dye molecules had a significant problem that only $1 \%$ of incident light was absorbed. Hence using a nanoporous $\mathrm{TiO}_{2}$ electrode with dye molecules incremented the lightharvesting efficiency and in 1991 the efficiency of the cell increased to 7\% [4]. 
In 1978, the first OSC was made with a single material (merocyanine) sandwiched between $\mathrm{Ag}$ and $\mathrm{Al}$ electrodes (very low efficiency, half percent). The thermal energy at room temperature was not able to fragment the excitons in OSCs by the photon absorption into free electrons and holes. So an external force was needed for the fragmentation process. So, in 1986 Tang presented an electron donor-acceptor concept and raises the efficiency to $\sim 1.0 \%$ [2]. Solidstate dye-sensitized solar cells (ss-DSSCs) which contain $\mathrm{Sn}^{2+}$-substitutability to $\mathrm{ZnO}$ nano-powder are composed by a co-precipitation method [3]. This type of cell improved power conversion efficiency from $3.0 \%$ for the cell with pure $\mathrm{ZnO}$ to $4.3 \%$ for the cell with $5 \% \mathrm{SnO}$ substitution. There are some different semiconductors designed for effective DSSCs [4]. Dyesensitized solar cell was fabricated using ( $\mathrm{Mn}$ and $\mathrm{Co}$ ) $\mathrm{Mn}$-doped $\mathrm{TiO}_{2}$ electrodes by using the hydrothermal method [5]. The effect of $\mathrm{Mn}^{2+}$ and $\mathrm{Co}^{2+}$ ions content on the properties of $\mathrm{TiO}_{2}$ electrodes was studied [5]. Also, the low-temperature hydrothermal process has been developed to synthesize titania nanorods (NRs) and nanoparticles (NPs) with controlled sizes for dyesensitized solar cells (DSSCs). The effect of calcination temperature on the performance of $\mathrm{TiO}_{2}$ nanoparticles for solar cells was investigated and discussed [6]. Finally, we must know, there are some different methods to obtain $\mathrm{TiO}_{2}$ nanoparticles from where the shapes of titanium dioxide, usage, dye-sensitized solar cells [7].

Bulk heterojunction (BHJ) enhances the organic cell where two types of organic substance that idealize donor and acceptor are mixed and liquefied in a solvent to produce the active layer. Recent research [8] showed that BHJ can effectively improve efficiency by $4-6 \%$. The $4^{\text {th }}$ generation of solar cells is expected to have very high efficiency (PCE); they can also be prepared in a large area with great ease like DSSCs and OSCs. This type of solar cells includes the organic-inorganic hybrid [2]. In this paper, a comparison between the three major types of excitonic solar cells (dye-sensitized, organic, and hybrid organic-inorganic solar cells) is carried out. The fabrication process, structural design, and theory of operation of these three types are presented in sections II, III, and IV, respectively. Conclusions are summarized in section 3 .

\section{Types of Excitonic Solar Cells}

\subsection{Dye-Sensitized Solar Cell "DSSC" 2.1.1 Theory of Operation}

Dye is excited by an absorbent photon. The start of the absorption is about $720 \mathrm{~nm}$ for most dyes as figure
1 "photon energy $1.72 \mathrm{eV}$ ". The lifetime of the animated state takes place in nanosecond range [9]. An electron is passed through complete cycles of excitation. An electron is injected to the conduction band (C.B.) of $\mathrm{TiO}_{2}$ by dye like in figure 2 . The rate of the injection occurrences in the femtosecond range "for singlet state" and triplet state is slower. So the power level of the triplet state is only lightly above (C.B.) edge of $\mathrm{TiO}_{2}$. Consequently, the electron transfer probability is lower. The dye energy level must be between $0.2-0.3 \mathrm{~V}$ above $\mathrm{TiO} 2$ conduction band edge to improve the injection process. "The back reaction" is the reduction of iodine at the counter electrode and the reduction of oxidized dye which occurs by electrons in the conduction band. This reaction occurs in ( $\mu \mathrm{s}-\mathrm{ms}$ range) and it is the main cause for the charge separation [9]. Finally, the electron diffuses in the electrolyte. It regenerates the oxidized dye, nano-porous $\mathrm{TiO}_{2}$ layer contains aspheric anatase particles made with a diameter of $20-30 \mathrm{~nm}$, band gap of $3.2 \mathrm{eV}$, and the thickness of the layer 10 $\mu \mathrm{m}$. The material is weakly $\mathrm{n}$-doped because of the presence of oxygen in the lattice. So, the front electrode contains approximately $10^{15}$ particles:

$\mathrm{V}_{\text {particle }}=\frac{4}{3} \quad \pi^{3}$
$\mathrm{n}_{\text {particle }}=\frac{\text { Vparticle }}{\text { Vlayer }} * \mathrm{P}_{\text {layer }}$

Where: $\mathrm{V}_{\text {particle: }} \mathrm{TiO}_{2}$ volume particle $/ \mathrm{m}^{-3}, \mathrm{r}:$ radius $(\mathrm{m}), \mathrm{n}_{\text {particle: }}$ number of particles of $\mathrm{TiO}_{2}$ in layer, $\mathrm{V}_{\text {layer }}$ : layer volume $/ \mathrm{m}^{-3}, \mathrm{P}_{\text {layer }}$ : the layer porosity.

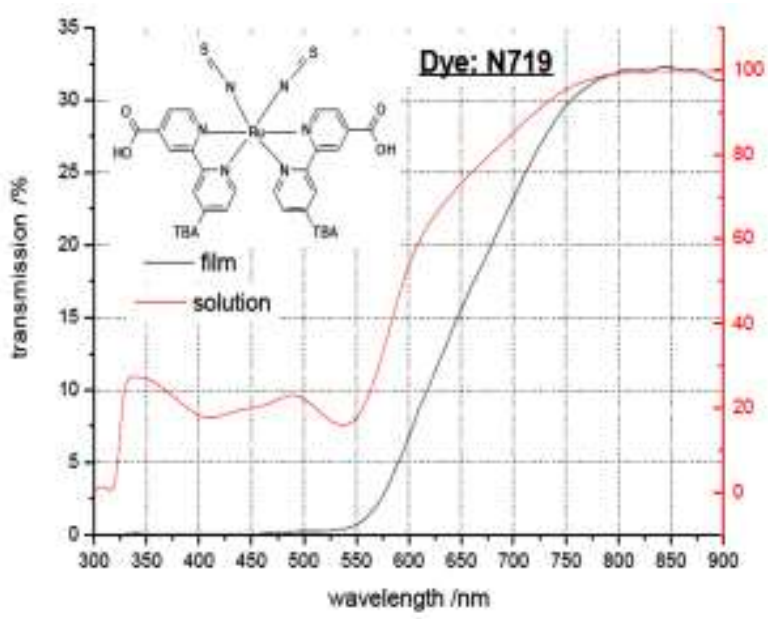

Fig. 1 Absorption spectra of N719 in solution and absorption on $\mathrm{TiO}_{2}$ surface [9].

According to the huge number of spherical particles, $\mathrm{TiO}_{2}$ is too small for a macroscopic electric field to build up, so electrons in the $\mathrm{TiO}_{2}$ layer are transported by using diffusion. The electron remains in the trap "waiting time T" before it is thermally activated to the 
$\mathrm{TiO}_{2}$ conduction band and jumps to a neighboring trap site depending on the depth of the trap state. Fick's law of diffusion is:

$\frac{\delta n}{\delta t \delta A}=-\mathrm{D}_{\mathrm{eff}} * \frac{\delta c}{\delta x}$

where: n: number of electrons, t: time $/ \mathrm{sec}, \mathrm{A}: \mathrm{area} / \mathrm{cm}^{2}$, $D_{\text {eff: }}$ effective diffusion coefficient $/ \mathrm{cm}^{2} \mathrm{~s}^{-1}, \quad \mathrm{C}$ : concentration of electrons $/ \mathrm{cm}^{3}$. The diffusion length $\left(D_{1}\right)$ must be at least as long as the thickness of the $\mathrm{TiO}_{2}$ electrode:

$\mathrm{D}_{1}=\sqrt{D e f f * \text { Tel }}$

where: $\mathrm{D}_{\mathrm{l}}$ :diffusionlength/cm, Tel: electron lifetime/sec

The electron moves through the outer electrical circuit and performs work, The electron at the counter electrode is transferred to a hole conducting medium. A lot of DSSC uses an iodide/iodine redox couple "reduction-oxidation". A thin layer of platinum spurs the reduction. The renewal of the oxidized dye is 100 times quicker than the recombination reaction "in the Nanosecond range". The loss of about $600 \mathrm{mV}$ due to the energy mismatches between the dye and the Redox couple is the main limitation for the low open-circuit voltage of DSSCs".

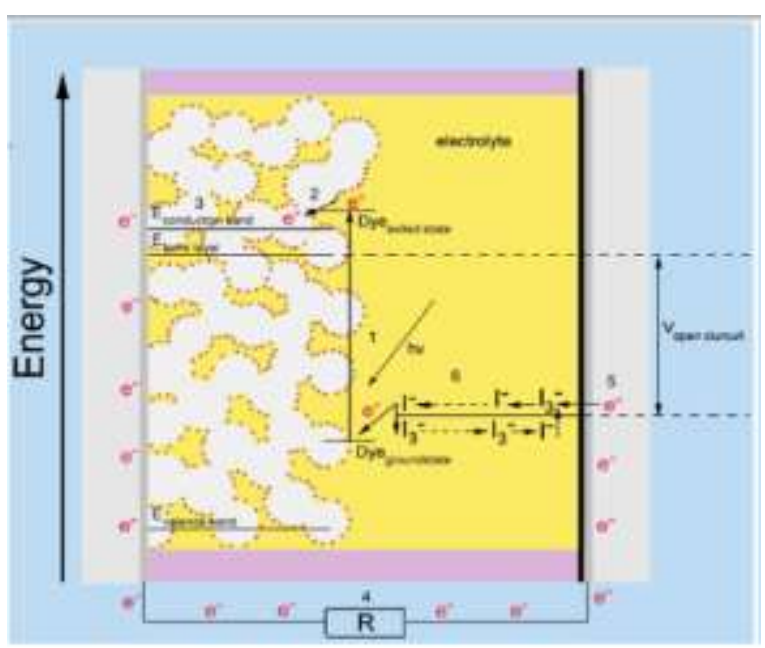

Fig. 2 Operation principle of dye-sensitized solar cell [9].

\subsubsection{Structural Design}

A glass slide can be painted with carbon nano-tube (CNTs) "an active electrode" "working electrode", that is set against another glass slide "counter terminal" as demonstrated in figure 3 . The space between these electrodes contains solid electrolyte which is a high conductance medium.

\subsubsection{Fabrication process}

DSSCs are arranged from third-era sun-based cells [2]. The future examination will include the fuse of quantum specks rather than the natural color as a sensitizer. Quantum dabs have the benefits of giving tunable band holes and the capacity to ingest explicit frequency. A few materials and procedures have been utilized, for example, designed semiconductor quantum spots, metal-free natural colors, and C60. Ongoing procedures utilized carbon nanotubes as a proxy. These cylinders "given by CVD strategy" are profoundly conductive, precisely solid, and photoactive. The cathodes come about because of utilizing natural fluids ionic arrangements with I-/I- ${ }^{3}$, which cooperate with the terminal and cause consumption. Utilizing platinum as a counter terminal is awkward for use as an honorable metal [1]. The way toward making the sunlight-based cells started with two glass plates covered with Fluorine Tin Oxide (FTO). This meager semiconducting layer permits charge to stream since the glass itself is nonconductive. First, the plates were tried to track down the conductive side of the glass. Titanium Dioxide is applied to the conductive side of one plate by utilizing a glass bar and moving it on the plate until a slick covering is accomplished [10].

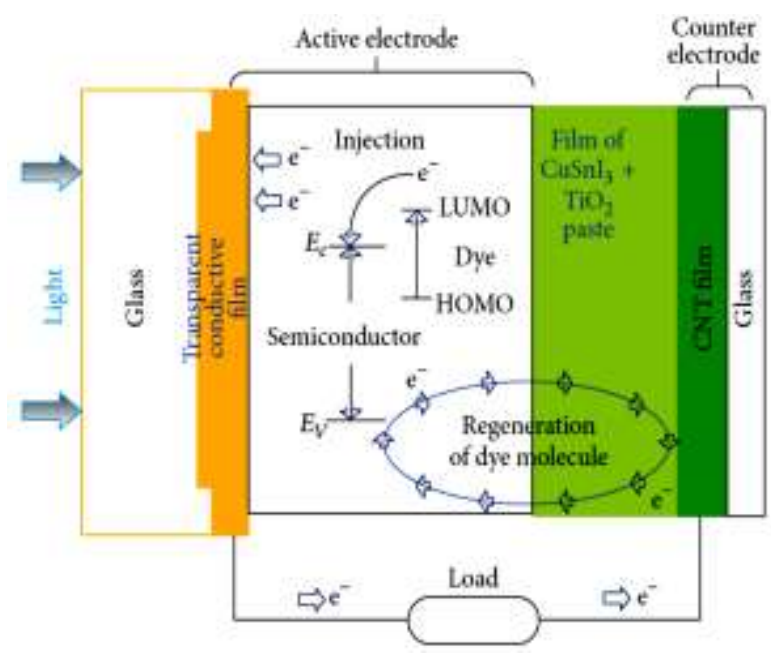

Fig. 3 The proposed dye-sensitized solar cells [1].

The tape is considering a uniform thickness of the $\mathrm{TiO}_{2}$ film as the $\mathrm{TiO}_{2}$ glue will occupy the space underneath the tape, when the glass bar is turned over. A comparable piece of glass ought to likewise be put straightforwardly in contact (at the base) with the plate so the titanium dioxide glue may have a slick covering to the edge. This plate is then positioned over a Bunsen burner for around 30 minutes with the goal that the $\mathrm{TiO}_{2}$ is attached to the plate. This cycle is called sintering and electron stream occurred. Following the sintering 
interaction, the plate is permitted to cool and is then positioned in a shower of the color Strawberries answer for 30 minutes [10]. This significance of the $\mathrm{TiO}_{2}$ nanoparticles becomes an integral factor. The expanded surface region takes into account a more noteworthy measure of color particles to be retained. The measures of electrons permitted to move through the framework are reliant upon the quantity of color. The more noteworthy surface territory means an expanded progression of power. In the wake of engrossing the color, the plates are set to dry and bond. The base plate is set in a hood (conductive side up) so the counter terminal as the slight carbon sediment or platinum glue might be applied. The cells are splashed with the goal that an in any event, covering is accomplished. The electrolyte arrangement is then positioned on the colored side of the plate, enough to immerse the surface. The two plates are sandwiched together (conductive sides contacting) and got with cover cuts. The cells are presently fit to be tried [10].

Another manufacture of DSSC utilized winged serpent organic product color as a sensitizer. The properties of winged serpent natural product color have been examined by UV-Vis and FTIR strategy. The $\mathrm{TiO}_{2}$ sheet resistivity increment from 1 layer $=22.1 \Omega \mathrm{cm}$ to 2 layers $=369.6 \Omega \mathrm{cm}$ after utilizing mythical beast natural product color. By this kind of DSSC, the productivity was assessed and mimicked utilizing a specially crafted procedure. Dropper has been utilized to gather color shade at the focus of the test cylinder and use for Fourier transform infrared spectroscopy (FTIR) and ultraviolet-obvious spectroscopy (UV-Vis) examinations. In this type, a porous film $\mathrm{TiO}_{2}$ paste is prepared using the technique reported by Wongcharee et al., 2007. Platinum (Pt) plated glass is prepared by the sputtering deposition technique [11].

\subsection{Organic solar cell}

\subsubsection{Theory of Operation}

This solar cell had a donor-acceptor bilayer structure. A thin film of electron acceptor material was coated on the light-absorbing material, which worked as an electron donor as shown in figure 4 [12]. At the donor-acceptor interface, electron acceptor material provided the necessary force to break the excitons into free charge carriers. The donor-acceptor concept was the most important finding for OSCs and led to more efficient solar cells when the donor-acceptor materials were mixed. To improve the excited electrons and holes diffusion length in OSCs, we must show the energy difference between the LUMO and HUMO of the acceptor and donor [8]. For the separation of electronhole carriers in the active layer, the electrons in the donor should be donated to the acceptor and the holes should be left in the donor itself. Even if the excitons are produced in the acceptor, the electrons should remain on the acceptor and the holes should be transferred to the donor. The materials having low ionization potentials (Ip) can easily donate the electrons. Therefore, they can serve as electron donors, whereas those with high electron affinities (Ea) can easily take electrons and serve as electron acceptors. Where LUMO offset should be equal to the exciton binding energy, the energy offset between HOMOs should be high enough to prevent hole transfer from donor to acceptor. The electron acceptors should possess high electron mobilities, whereas the donors should have high hole mobilities. Apart from the active layer, the transport layers are also equally important and should have high electron-hole mobilities with energy levels that introduce no barriers for charge extraction.

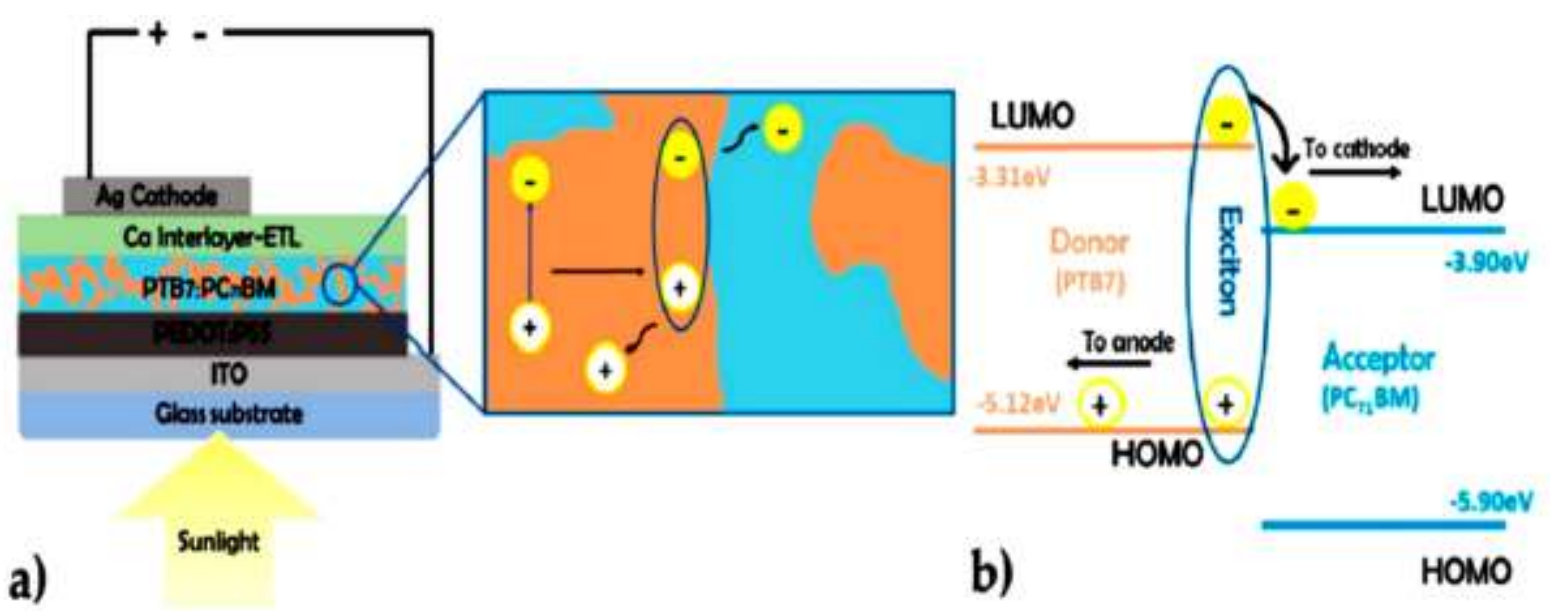

Fig. 4 Structure of the bulk heterojunction organic solar cell [12]. 
During device fabrication, the deposition of one material should not affect in any way the underlying film [2]. The operation of a bulk heterojunction solar cell is dependent on four automation [12]:

(a) Light absorption: photons are absorbed by the photoactive layer, which consists of an electron donor material (PTB7) and an electron acceptor material (PC71BM) that mixed together, (b) Charge generation: a photon is absorbed by the donor material. The hole and electron are linked and form a quasi-particle known as an exciton, (c) Charge separation: The free transport layers are also equally important and should have high electron-hole mobilities with energy levels that introduce no barriers for charge extraction. During device fabrication, the deposition of one material should not affect in any way the underlying film [2].

\subsubsection{Structural Design}

Mixing of donor-acceptor materials forms lots of junctions in a single layer and it is known as the bulkhetero-junction (BHJ) as shown in figure 5. There is some architecture of (OSCs) such as Normal Geometry OSCs, Inverted Geometry OSCs, Bulk-Hetero-junction (BHJ) Structure, Hybrid Planar-Mixed Hetero-junction Structure, p-i-n Structure, Single Layer OSC, Dual Layer OSC, and Tandem Structure [2]

Structural design of OSCs is part of the significant measures to improve efficiencies [8]. The works on apparatus composition implemented by tang, the bandgap between high occupied molecular orbital (HOMO) and lowest occupied molecular orbital (LUMO) of the polymer; granted exciton separation more efficient in the hetero-junction structure interfaces. Fullerene in OSC is the good. Bulk heterojunction concept pretended better efficiencies than bilayer due to more excitons are achieved in this installation [8].

The traditional structure of ITO/PEDOT: "PSS/active layer/Ca/Al" was used to fabricate the OPV device. Then the mixture of PffBT4T2OD:PC71BM was spin-coated from the solution of the solvent mixture with a total concentration of $20 \mathrm{mg} / \mathrm{ml}$. After 3 hours of drying, one film group was annealed at $100^{\circ} \mathrm{C}$ for 5 minutes. Then the electrodes are composed of calcium $(5 \mathrm{~nm})$, and aluminum $(100 \mathrm{~nm})$ was evaporated in a thermal evaporator. Finally, the device was encapsulated using a glass bracket and UV-cured epoxy [13].

\subsubsection{Fabrication process}

OSCs can be created R2R on plastic sheets at room temperature [2]. Warm dissipation in vacuum and arrangement handling are the most regularly utilized strategies to manufacture OSCs. There are numerous strategies to plan thin films from solutions; however, spin coating and inkjet printings are the most utilizing procedures.

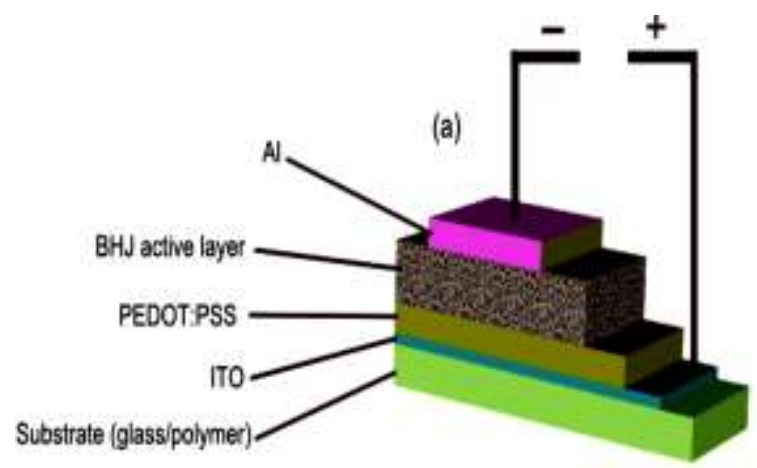

Fig. 5 bulk-heterojunction (BHJ) device structure [2].

Spin coating is a solution-processed fabrication process to coat thin film which can give high accuracy. This technique is simple and low cost but more than $90 \%$ material losses while doing the spinning process [8]. Sometimes dip coating and screen printing techniques are additionally utilized for this reason. Inkjet printing process is the most important technique which can produce very large-area devices with roll-toroll (R2R) processing. Inkjet printing is a cost-effective way for production without any material loss and it is the first choice for industrial production. Another technique is spray coating. It is easier than doctor blading. The bad of spray coating is using a large blob onto the substrate, resulting in varied surface roughness. The surface roughness is $10 \mathrm{~nm}$ compared to blading or spin coating technique. Although the surface of the thin film is more indelicacy using spray coating, but fully functional devices and coherent film have been obtained by using this method [8]. The diffusion length of exciton of natural semiconducting materials has been appraised by utilizing various strategies, like volume quenching, surface quenching, exciton-exciton annihilation, spectra, and photovoltage measurements. We have recently shown that warm tempering and dissolvable fume toughening are viable to improve the exciton dissemination for some natural contributor materials [13].

\subsection{Hybrid solar cell}

\subsubsection{Theory of Operation}

The operation for inorganic/organic hybrid solar cells is more complex. The external quantum efficiency (EQE), can be written as:

$\mathrm{EQE}[\eta, \mathrm{V}]=\eta_{\mathrm{A}}[\lambda] \times \eta_{\text {diff }} \mathrm{x} \eta_{\text {diss }}[\mathrm{V}] \eta_{\mathrm{tr}} \mathrm{x}[\mathrm{V}] \mathrm{x} \eta_{\mathrm{cc}}[\mathrm{V}]$ 
where: $\lambda$ : the wavelength of the incident light, $V$ : the voltage across the cell, $\eta_{\mathrm{A}}(\lambda)$ : the photon absorption yield. $\eta_{\text {diff: }}$ is the exciton diffusion [15]. This efficiency may be increased by two factors: (1) Reducing the average donor/acceptor distance according to the active layer, (2) Increasing the exciton diffusion length. $\eta_{\text {diss }}(V)$ : is the exciton dissociation, $\eta_{\text {tr }}(V)$ : is the charge transport, and $\eta \mathrm{cc}(\mathrm{V})$ : is the charge collection.

Structural defects and impurities in the active layer caused the carriers to trap and recombine, so reduces the transport efficiency. $\eta$ tr can be increased by: a) Increasing the crystalline and the size of donor and acceptor components, b) Reducing energetic barriers between like domains in the active layer, and c) Applying a reverse bias on the device [16]. There are some strategies to overcome the disadvantages of this kind of cell, such as in situ growth of quantum dots; ligand exchange, thermally cleavable ligands, novel surfactants, and polymerization of polymers on a quantum dot surface have also been employed. These methods led to better PCE in hybrid solar cells. For example, the growth of CdS quantum dots in P3HT resulted in direct interconnection and good contact between P3HT and CdS quantum dots, giving much higher Voc and (Jsc) compared to a normal blending of CdS quantum dots with P3HT. The maximum PCE achieved so far in hybrid solar cells is $5.5 \%$ that employed a low band gap polymer poly (PDTPBT) as the donor and nano-crystals of $\mathrm{PbS}_{\mathrm{x}} \mathrm{Se}_{1-\mathrm{x}}$ as the acceptor.

\subsubsection{Structural Design}

The structure and working principle of hybrid solar cells are similar to OSCs, except that the electron acceptors in hybrid solar cells are crystalline nanostructures of inorganic semiconductors. The excitons generated in the polymers on light absorption get dissociated at the polymer-inorganic nano-crystal interfaces where electrons get transferred to inorganic nanocrystals and the holes remain in the polymer. Electrons transport through nano-crystalline inorganic semiconductor channels and holes transport through polymer channels to collect at the special [2]. Because of the band gap tuning of quantum dots and nanoparticles through variation in their size, therefore, use of quantum dots and nanoparticles with polymers would have additional advantages of energy level matching with other constituents and harvesting the solar energy from the regions where the polymer does not absorb. The mixing of quantum dots and nanostructures with conjugated polymers for efficient photon harvesting is not simple. Physical contact of nanostructures and conjugated polymers is important to charge separation and transportation. The charge separation and migration of charge carriers is strongly affected by the interfacial contacts. So, the interface and interaction between polymers and nanostructures are very important [2].

\subsubsection{Fabrication process}

High PCE in OSCs required the donor/acceptor materials of broad absorption spectra and high charge carrier mobilities. On the contrary, the low charge carrier mobilities in organic semiconductors had always been a serious concern. As the inorganic semiconductors have high charge carrier mobilities, high thermal stability, and high photoconductivity, they drew the attention of researchers toward their possible use in OSCs [2]. Interfacial charge separation in OSCs is critical, and it requires a large interfacial area for efficient charge separation. Therefore, for the use of inorganic semiconductors and conjugated polymers, they have been grown in nano-crystalline structures and incorporated as electron acceptors to formulate the solar cells.

The solar cells having both organic and inorganic semiconductors as electron donors and acceptors are known as organic-inorganic hybrid solar cells. The hybrid solar cells use high electron mobility of inorganic nanocrystals and wide-range absorption and solution processability of conjugated polymers. Additionally, the combined absorption spectrum of organic-inorganic semiconductors in the composite improves photon harvesting. The relative energy levels of donor/acceptor materials in hybrid solar cells are of high importance as the photocurrent of the solar cells depends on the energy level alignment at both the donor-acceptor and electrode interfaces. Therefore, in mongrel solar cells, selecting organic-inorganic semiconductors along with suitable electrodes is crucial. To deal with the issues of charge separation and transportation in hybrid solar cells, some of the important inorganic semiconducting nano-materials that have been used as electron acceptors are CdSe, CdTe, $\mathrm{ZnO}, \mathrm{CdS}, \mathrm{ZnS}, \mathrm{TiO}_{2}, \mathrm{PbS}$, and $\mathrm{PbSe}$ [2].

\section{A comparison table for different related}

\section{works in the literature}

We can compare the literature reviews between organic, dye sensitized, and hybrid solar cells as shown in Table 1. 
Table 1. Comparison table for different related works in literature.

\begin{tabular}{|c|c|c|}
\hline Dye Sensitized Solar Cell & Organic solar cell & Hybrid solar cell \\
\hline 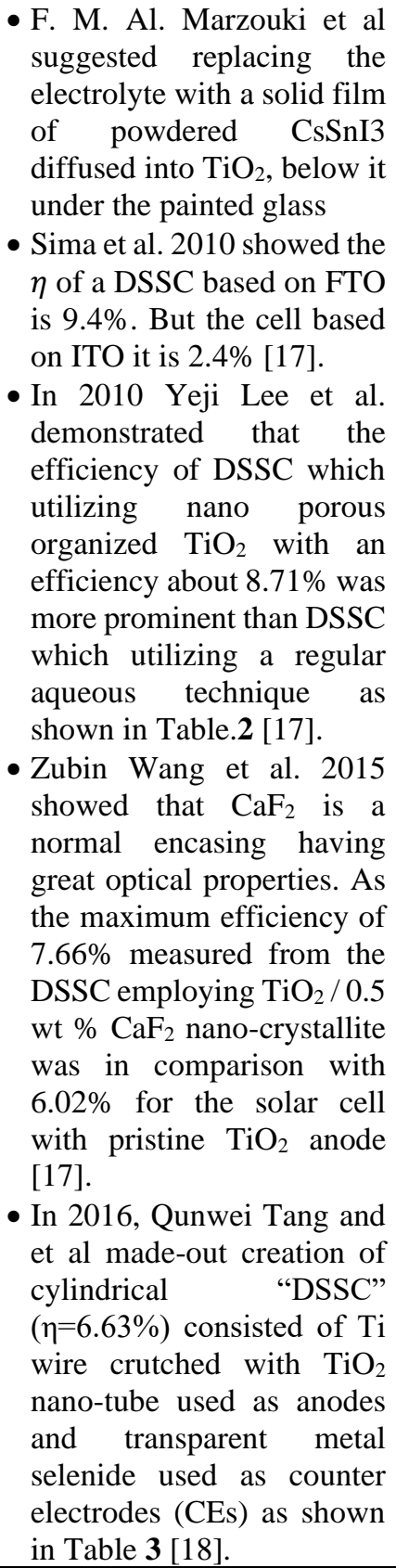 & $\begin{array}{l}\text { - Germa Garcia-Belmonte } 2010 \\
\text { shows the Voc as a relation to } \\
\text { temperature and light intensity } \\
\text { using a recently published model. } \\
\text { The outcomes were contrasted } \\
\text { and test temperature coefficients } \\
\text { of Voc revealed for BHJ organic } \\
\text { solar cells. He deduced that there } \\
\text { is a straight connection among } \\
\text { Voc and-T. so when the negative } \\
\text { temperature coefficients are } \\
\text { formidable, a little Voc at low } \\
\text { light intensity values [17]. } \\
\text { - M.C. Scharber, N.S. Sariciftci in } \\
\text { 2013 shows that, Bulk hetero- } \\
\text { junction devices offering only } \\
\text { radiative recombination of } \\
\text { carriers could be as aptness as } \\
\text { ideal inorganic photovoltaic } \\
\text { devices [19]. } \\
\text { - Nurul Bariah Idris et al in } 2015 \\
\text { had shown the development in } \\
\text { organic solar cell devices. } \\
\text { Whereby improve in } \\
\text { performances from } 1 \% \text { up to } 10 \% \\
\text { efficiency rivalling with thin film. } \\
\text { The performance can be } \\
\text { appointed due to progress } \\
\text { research in new conjugated } \\
\text { organic polymer material used as } \\
\text { active layer in organic solar cell } \\
\text { [8]. }\end{array}$ & $\begin{array}{l}\text { - Pang-Leen Ong and Igor A. Levitsky } \\
\text { introduce a review based on organic } \\
\text { semiconductor (Group IV, III-V), } \\
\text { which separately from dye } \\
\text { synthesized, polymer metal oxides } \\
\text { and organic inorganic (Group II-VI) } \\
\text { nanocomposites photovoltaic in } \\
\text { 2010. The structure of this cell } \\
\text { consists of an organic active material } \\
\text { (p-type) deposited by different } \\
\text { methods like: coating, spraying, or } \\
\text { printing processes on the surface of } \\
\text { bulk or nanostructured } \\
\text { semiconductor (n-type) forming a } \\
\text { hetero-junction between the two } \\
\text { materials. They organized the types } \\
\text { of hybrid PVs depending on the } \\
\text { nature of organic-inorganic } \\
\text { component and the morphology of } \\
\text { the devices "figure 9". DSSC possess } \\
\text { the highest efficiency (up to } 11 \% \text { ) } \\
\text { between organic and hybrid PVs. } \\
\text { Electron mobility in metal oxide } \\
\text { semiconductors is higher than in } \\
\text { organic systems. However, the } \\
\text { efficiency for these PVs is low (0.1- } \\
\text { 0.6) [20]. } \\
\text { Lewis et al. described a Si-polymer } \\
\text { solar cell which prepared by coating } \\
\text { of poly-(CH3)3 } 3 \text { Si- } \\
\text { cyclooctatetracene over crystalline Si } \\
\text { surface with efficiency from } 1 \% \text { to } \\
\text { 5\%. The achieved Voc is } 0.64 \mathrm{~V} \text { and } \\
\text { it is good agreement with theoretical } \\
\text { calculations. The short circuit current } \\
\text { was a few nA range. The use of } \\
\text { organic small molecules to Form } \\
\text { betero-junctions studied [20]. }\end{array}$ \\
\hline
\end{tabular}


Table 1. (continued)

\begin{tabular}{|c|c|c|}
\hline Dye-Sensitized Solar Cell & Organic solar cell & Hybrid solar cell \\
\hline $\begin{array}{l}\text { - In 2011, Eric Arsenault made } \\
\text { out manufacturing an all-in- } \\
\text { one integrated DSSC in } \\
\text { which the electrode is } \\
\text { outreached to the active area } \\
\text { of the solar cell to increase } \\
\text { the speed of moving } \\
\text { electrons to the electrode to } \\
\text { improve the conversion } \\
\text { efficiency. Titania films were } \\
\text { produced by doctor blading } \\
\text { technique where three slides } \\
\text { are collected in an (H) letter } \\
\text { like figure } 6 \text { [21]. } \\
\text { - While in } 2020, \text { Abdelkhalk et } \\
\text { al showed Synthesis } \\
\text { methods. They find that the } \\
\text { efficacies of solar cells } \\
\text { calculated as } 2.44 \%, 3.94 \% \text {, } \\
\text { and 7.67 \% with TiO } \\
\text { synthesized across flame } \\
\text { spray pyrolysis method, } \\
\text { hydrothermal sol-gel method } \\
\text { and reference Titania } \\
\text { electrode, respectively [22]. } \\
\text { - In 2012 Liao et al. proved } \\
\text { that DSSC has an } \eta \text { of } 9.35 \% \\
\text { with a photo-electrode based } \\
\text { on the hierarchical anatase } \\
\text { TiO2 spheres, however, } \eta \text { of } \\
\text { DSSC is based on } \\
\text { nanoparticles "7.37\%", } \\
\text { nanofibers " } 8.15 \% ", \text { and } \\
\text { ellipsoid TiO2 spheres } \\
\text { "7.93\%" [17]. In } 2017, \text { Marina Freitag et al. } \\
\text { showed that (DSC) } \\
\text { accomplished outside } \\
\text { quantum productivity } \\
\text { surpasses 90\% across the } \\
\text { entire obvious space from } \\
400 \text { to } 650 \text { nm, and } \\
\text { accomplished force yields of } \\
15.6 \text { and } 88.5 \mu W / \text { cm2 at } 200 \\
\text { and 1,000 lux. This } \\
\text { converted into a PCE of } \\
28.9 \%[17] .\end{array}$ & 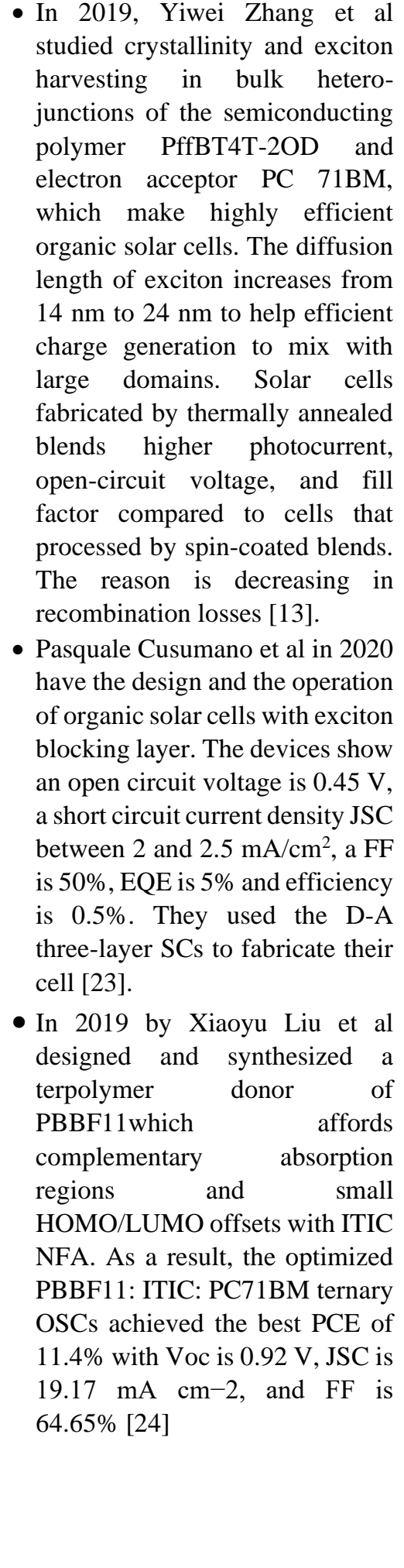 & 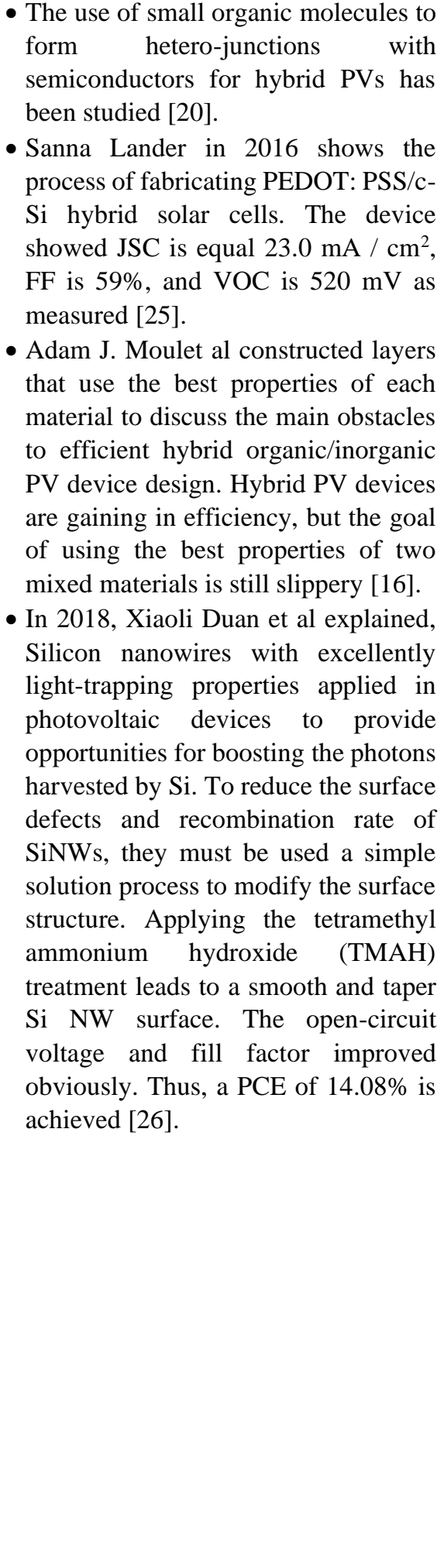 \\
\hline
\end{tabular}


Table 1. (continued)

\begin{tabular}{|c|c|}
\hline ar Cell & solar cell \\
\hline $\begin{array}{l}\text { - In 2018, Menah Allah Samy et al. } \\
\text { compared DSSC with different wave } \\
\text { length (460,500, 532, 540, 570, 589, and } \\
\text { sunlight radiation). They found that, DSSC } \\
\text { gives the maximum current and maximum } \\
\text { power for } 460 \mathrm{~nm} \text { at certain intensity } \\
\left(17.577 \mathrm{~W} / \mathrm{m}^{2}\right) \text { at room temperatures such } \\
\text { as figures } 7 \text { and } 8[17] \text {. } \\
\text { - V.G. Maratin et al made out in } 2020 \text { the } \\
\text { comparison of performance of DSSCs } \\
\text { which used Degussa P25 and anatase } \mathrm{TiO}_{2} \\
\text { films as photo-anode of the device. It is } \\
\text { found that the DSSC using Degussa P25 } \\
\text { pretended higher performance " } \eta \text { of } \\
1.28 \% \text { " than that of the device which used } \\
\text { anatase TiO2 " } \eta \text { of } 0.447 \% \text { " [19]. } \\
\text { - Also in } 2020 \text {, M.J. Jimmy et al showed that } \\
\text { the DSSC using the } 0.3 \mathrm{mg} / 1 \text { seaweed dye } \\
\text { produces the highest Jsc of } 0.0183 \mathrm{~mA} / \\
\text { cm2 while the device which using } 0.5 \mathrm{mM} \\
\text { rose bengal dye demonstrates the highest } \\
\text { Jsc that is } 0.1436 \mathrm{~mA} / \mathrm{cm}^{2}, \text { the rendition of } \\
\text { the device which using rose bengal dye is } \\
\text { higher than that of the device using } \\
\text { seaweed dye, and the efficiency of the } \\
\text { device using two types of dyes is low [27]. }\end{array}$ & $\begin{array}{l}\text { - While in } 2019 \text { Rongbin Xie et al made out a solution-based } \\
\text { hetero-junction technology is emerging for facile } \\
\text { fabrication of silicon (Si)-based solar cells. They } \\
\text { developed a facile and repeatable method to passivate the } \\
\text { Si surface by a simple } 1 \text {-min annealing process in vacuum, } \\
\text { and integrated it into the hetero-junction cells with } \\
\text { poly(3,4-ethylenedioxythiophene): poly(styrenesulfonate) } \\
\text { (PEDOT:PSS) or carbon nanotube (CNT). A thin and } \\
\text { dense oxide layer was introduced on the Si surface to } \\
\text { provide a high-quality hole transport layer and passivation } \\
\text { layer. The layer enhanced the efficiency from } 9.34 \% \text { up to } \\
\text { 12.87\% for the PEDOT: PSS/n-Si cells and from } 6.61 \% \text { up } \\
\text { to } 8.52 \% \text { for the CNT/n-Si cells. FFs of } 0.73 \text { and } 0.58 \text {, } \\
\text { increased respectively [28]. } \\
\text { - Guiqiang Li et al in 2018 analyses the feasibility of } \\
\text { photovoltaic-thermoelectric (PV-TE). They present the } \\
\text { efficient improvement of PV-TE in actual application. In } \\
\text { particular, a novel PV-TE system using a flat plate micro- } \\
\text { channel heat pipe has shown potential to help reduce the } \\
\text { quantity of TEG used significantly. So reduce the overall } \\
\text { cost of the system. This review shown, the optimal design } \\
\text { parameters for a TEG only system might not be the same } \\
\text { for a hybrid PV-TE system [29]. }\end{array}$ \\
\hline
\end{tabular}

Table 2. Conversion efficiencies of DSSCs fabricated with nano-sized and nano-porous $\mathrm{TiO}_{2}$

\begin{tabular}{|c|c|c|c|c|c|}
\hline Working electrode & Dye & Efficiency (\%) & Fill factor & Voc & Jsc \\
\hline Nano-sized $\mathbf{T i O}_{2}$ & N 719 & 7.03 & 0.68 & 0.72 & 14.36 \\
\hline Nano-porous $\mathbf{T i O}_{2}$ & N 719 & 8.71 & 0.67 & 0.78 & 16.66 \\
\hline p-25 TiO $_{2}$ & N 719 & 4.23 & 0.62 & 0.71 & 9.60 \\
\hline
\end{tabular}

Table 3. The efficiencies of the cylindrical DSSC with different CEs at an incident angle of 0

\begin{tabular}{|c|c|}
\hline The Cell with & Efficiency $(\boldsymbol{\%})$ \\
\hline CoSeCE & 6.63 \\
\hline FeSeCE & 3.05 \\
\hline NiSeCE & 5.12 \\
\hline PtCE & 2.84 \\
\hline
\end{tabular}




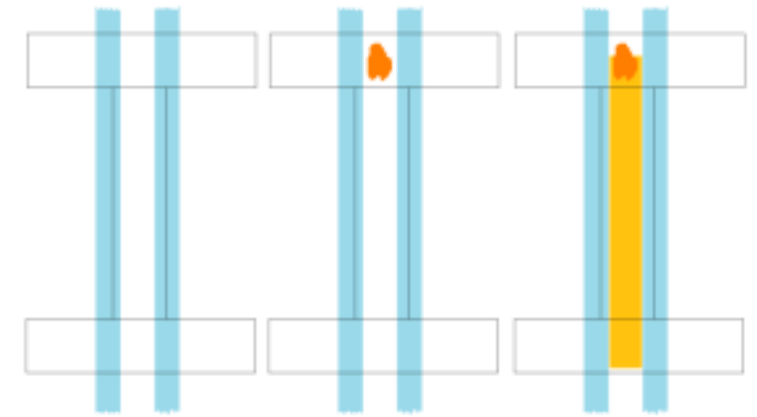

Fig. 6 The Doctor Blading technique [21].

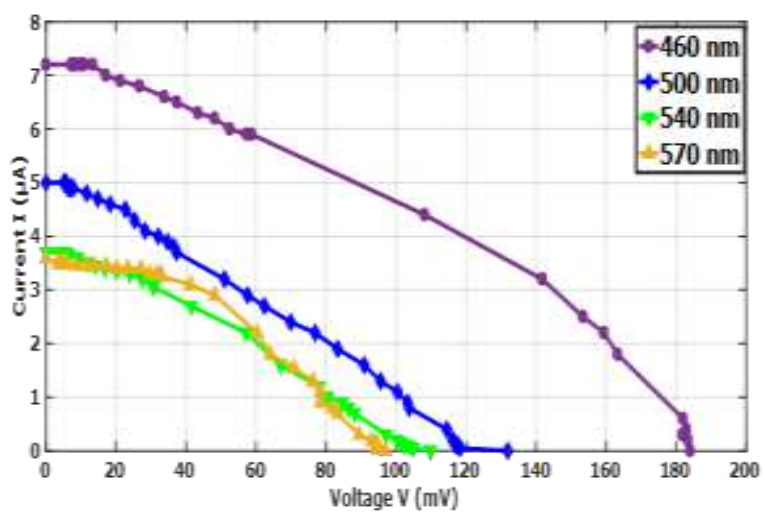

Fig. 7 Current-Voltage Characteristics for Dye Sensitized Solar Cell $\left(17.577 \mathrm{~W} / \mathrm{m}^{2}\right)$ [17].

\section{The preparation of different materials \\ applied for electrodes}

There are three main organic solar cells: dyesensitized or solar cells, polymer-based solar cells, and organic-inorganic hybrid solar cells. Usually, these are created by wet chemical processes and small-molecule organic solar cells (SM-OSCs), the focus of the current work. The first small-molecule organic solar cells have some advantages like a very cost-efficient, lightweight, large-area technology, possibly also on flexible, non-planar substrates. The first smallmolecule organic solar cells employing only PEDOT: PSS as transparent electrode [30]. Transparent contacting materials such as: ITO, $\mathrm{ZnO}: \mathrm{Al}$, and PEDOT:PSS. PEDOT:PSS led to better results compared to ITO [30]. But disadvantages of PEDOT:PSS are its susceptibility to oxygen, $\mathrm{H}_{2} \mathrm{O}$, sodium and UV-light. The current work's PEDOT:PSS molding was BAYTRON PH500 with 5\% dimethyl sulfoxide (DMSO) added to the aqueous solution. With addition of DMSO, a conductivity increase to $500 \mathrm{~S} / \mathrm{cm}$ was observed. The PEDOT:PSS bottles were kept in the dark in a refrigerator to prevent premature polymerization or degradation. To reduce viscosity, the

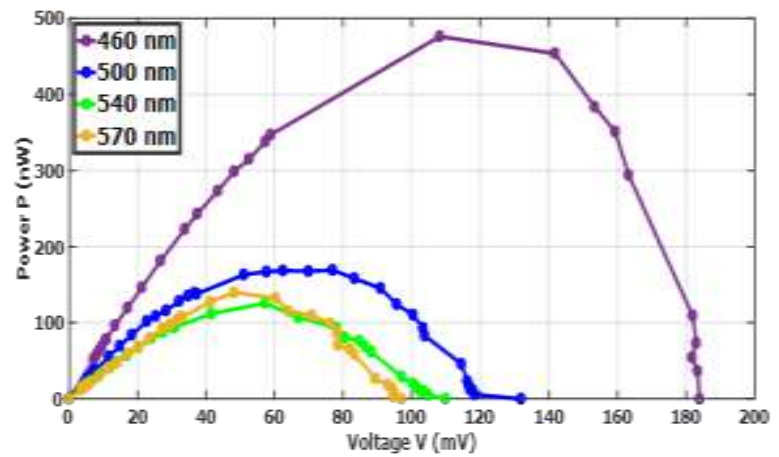

Fig. 8 Power-Voltage Characteristics for Dye Sensitized Solar Cell (17.577 W/m²) [17].

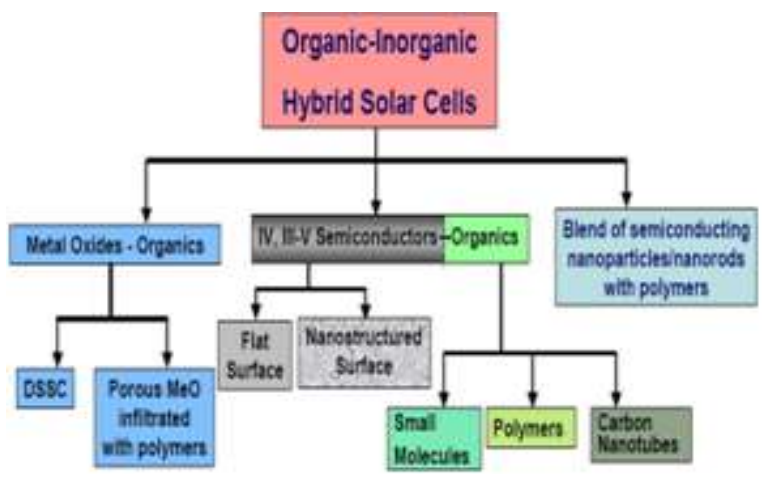

Fig. 9 Classification of hybrid solar cells [2].

bottles were removed from the fridge $24 \mathrm{~h}$ before processing. For some experiments, $10 \mathrm{wt} \%$ of the perfluorinated ionomer Nafion was added to the solution directly prior to spin coating. Substrates were 2.54 by $2.54 \mathrm{~cm}^{2}$ float glass pieces or PET foil. Glass substrates were cleaned by sonicating in Extron, deionized water, acetone, ethanol, and isopropanol; PET foil substrates were pre-structured with a laser printer and cleaned with de-ionized water and ethanol. To improve wetting, all substrates were treated in a UVoxygen plasma-etching system before spin coating. This removed further contamination and led to increased hydrophilicity and lower contact angles of the PEDOT:PSS solution on the substrate and was found essential for uniform and homogeneous films [30-33].

\section{Conclusion}

The solar cells passed through numerous steps, starting from simple solar cells, then solar cells based on thin film, and finally the third generation with flexible substrate and basic low-cost materials. After more than 25 years of research and development, organic solar cells are now a substantially improved technology. These improvements have increased the PCE of OPVs from $0.001 \%$ in 1975 (when the first 
OPV cell was described) to $8.6 \%$ in 2012 . In this survey work we see that the photograph age of a free-electron - opening for every cell. The analysis leads to amazing conclusions regarding the performance, materials, theory of operation, and fabrication techniques of each excitonic solar cells such as dye sensitized solar cells "DSSC", Organic solar cells, Hybrid Organic-inorganic "excluding perovskite" solar cells and collection comparison researches for each of them. As PCE increases, OPV research and technology will attract an army of researchers, resulting in cost reduction and replacing inorganic PVs by OPVs in many cases. Since markets demand that an efficiency of $10 \%$ or higher is necessary for commercial viability, the research efforts into OPVs continue in earnest. The three major advantages of using organic materials are: a) the expected high efficiency per unit cost ratio, b) the simplicity in fabrication and processing, and c) the mechanical flexibility of these materials. These advantages spur intensive research to overcome the shortcomings of OPVs. The limitations with respect to OPV efficiency stem from the short diffusion length and from low absorption of the active layer. These are just some examples of promising configurations that will enable organic solar cells to be economically competitive with conventional inorganic solar cells and perhaps replace them in the future.

\section{References}

[1] F.M. Al-Marzouki, S. Abdalla, and S. Al-Ameer, dye sensitized solar cells with low cost carbon nanotubes electrodes, Advances in Materials Science and Engineering, (2016) 1-14 https://doi.org/10.1155/2016/4928710

[2] W.A. Hammed, R.Yahya, A. L. Bola, and H. N. M. E. Mahmud, recent approaches to controlling the nanoscale morphology of polymer-based bulkheterojunction solar cells, energies, 6 (2013), 5847-5868. http://dx.doi.org/10.3390/en6115847

[3] A.N. El-Shazly, A.E. Shalan, M.M. Rashad, E.A. Abdel-Aal, I.A. Ibrahima and M.F. El-Shahatb, solid-state dye-sensitized solar cells based on Zn1_xSnxO nanocomposite photoanodes, RSC Advances, 8 (2018), 24059-24067.

[4] M. M. Moharam, A.N. El Shazly, K.V. Anand, D. EL Rahman, A. Rayan, M.K.A. Mohammed, M.M. Rashad, and A.E. Shalan, semiconductors as effective electrodes for dye sensitized solar cell applications, Topics in Current Chemistry, 20 (2021) 1-17

https://doi.org/10.1007/s41061-021-00334-w
[5] A.E. Shalan and M.M. Rashad, incorporation of $\mathrm{Mn}^{2+}$ and $\mathrm{Co}^{2+}$ to $\mathrm{TiO}_{2}$ nanoparticles and the performance of dye-sensitized solar cells, Applied Surface Science, 283 (2013) 975-981. https://doi.org/10.1016/j.apsusc.2013.07.055

[6] A.E. Shalan, M.M. Rashad, Youhai Yu, Monica Lira-Cantu, M.S.A. Abdel-Mottaleb, controlling the microstructure and properties of titania nanopowders for high efficiency dye sensitized solar cells, Electrochimica Acta, 89 (2013) 469478.

https://doi.org/10.1016/j.electacta.2012.11.091

[7] A. Esmail Shalan, A.M. Elseman and M.M. Rashad, controlling the microstructure and properties of titanium dioxide for efficient solar cells, Titanium Dioxide (ch. 18), (2018) 351-366

[8] Idris, N.B., M.N. Norizan, and I.S. Mohamad, organic solar cell: An overview on performance and fabrication techniques, in Applied Mechanics and Materials, 754-755 (2015) 540-545 https://doi.org/10.4028/www.scientific.net/AMM. $\underline{754-755.540}$

[9] J., M., novel aqueous electrolyte films for hole conduction in dye sensitized solar cells and development of an electron transport model. refubium - freie universitat berlin repository, (2007)

http://dx.doi.org/10.17169/refubium-17761

[10] M., A.A., A.S.S. Ahmad, and W.A. Azeez, fabrication of dye sensitized solar cell based on titanium dioxide $\left(\mathrm{Ti}_{\mathrm{O} 2}\right)$. Advances in Materials Physics and Chemistry, 5 (2015) 361-367 http://dx.doi.org/10.4236/ampc.2015.59036

[11] R. Ahmad, M.A. and N. Nayan, fabrication and analysis of dye-sensitized solar cell using natural dye extracted from dragon fruit. International Journal of Integrated Engineering, 3 (2010) 55-62

[12] K. Anagnosto, M.M. Stylianakis, K. Petridis, and E. Kymakis, building an organic solar cell: Fundamental procedures for device fabrication, Energies, 12 (2019) 1-23 http://dx.doi.org/10.3390/en12112188

[13] Y. Zhang, M.T. Sajjad, O. Blaszczyk, A.J. Parnell, A. Ruseckas, L.A. Serrano, G. Cooke, and I.D.W. Samuel, large crystalline domains and an enhanced exciton diffusion length enable efficient organic solar cells. Chemistry of Materials, 31 (2019) 6548-6557

https://doi.org/10.1021/acs.chemmater.8b05293

[14] E. Arsenault, three-dimensional transparent conducting oxide based dye sensitized solar cells, Masters of Science, Department of Chemistry University of Toronto, (2011). 
[15] A. Aboulouard, B. Gultekin, M. Can, M. Erol, A. Jouaiti, B. Elhadadi, C. Zafer, and S. Demic, dye sensitized solar cells based on titanium dioxide nanoparticles synthesized by flame spray pyrolysis and hydrothermal sol-gel methods: a comparative study on photovoltaic performances, Journal of Materials Research and Technology, 9 (2020) 1569-1577 https://doi.org/10.1016/j.jmrt.2019.11.083

[16] A.J. Moulé, L. Chang, C. Thambidurai, R.Vidu and P. Stroeve, hybrid solar cells: basic principles and the role of ligands, Journal of Materials Chemistry, 22 (2012) 2351-2368 https://doi.org/10.1039/C1JM14829J

[17] M.A. Abd El Gany, M.F.M. Hassan, M.D. Asham, and U.M.N. El Demerdash, comparative study of silicon and dye sensitized solar cells, thesis, 2018 1-102

[18] Q. Tang, L. Zhang, B. He, L. Yu and P. Yang., cylindrical dye-sensitized solar cells with high efficiency and stability over time and incident angle, Chemical Communications, 52 (2016) 3528-3531 https://doi.org/10.1039/C5CC10105K

[19] M., V., A. Harun, and M. Rahman, dye-sensitized Solar Cell utilizing degussa $\mathrm{P} 25$ and anatase $\mathrm{TiO}_{2}$ films: comparative study of photovoltaic performance: effect of N719 dye concentration, Int. J. Electrochem. Sci, 15 (2020) 1643-1654 http://electrochemsci.org/papers/vol15/15020164 $\underline{\text { 3.pdf }}$

[20] Ong, P.-L. and I.A. Levitsky, organic/IV, III-V semiconductor hybrid solar cells. Energies, 3 (2010) 313-334. https://eng.libretexts.org/

[22] S., M.C. and N.S. Sariciftci, efficiency of bulkheterojunction organic solar cells, Progress in polymer science, 38 (2013) 1929-1940

https://doi.org/10.1016/j.progpolymsci.2013.05.0 $\underline{01}$

[23] P. Cusumano, C. Arnone, M. A. Giambra and A. Parisi, donor/acceptor heterojunction organic solar cells, Electronics, 9 (2020) 1-8 https://doi.org/10.3390/electronics 9010070

[24] X. Liu, Y. Yan, A. Honarfar, Y. Yao, K. Zheng, and $\mathrm{Z}$. Liang, unveiling excitonic dynamics in high efficiency nonfullerene organic solar cells to direct morphological optimization for suppressing charge recombination, Advanced Science, 6 (2019) 1-10 https://doi.org/10.1002/advs.201802103

[25] L. and S., polymer/silicon hybrid solar cells: fabrication and electrical properties, thesis, 2016 https://www.divaportal.org/smash/record.jsf?pid $=$ diva2\%3A1039928\&dswid $=-5290$

[26] X. Duan, X. Zhang, and Y. Zhang, high performance organic-nanostructured silicon hybrid solar cell with modified surface structure, Nanoscale research letters, 13 (2018) 1-6 https://doi.org/10.1186/s11671-018-2703-2

[27] M.J. Jimmy, A.M. Harun, M.Y.A. Rahman, and N.A. Ludin, comparative study of dye-sensitized solar cell utilizing seaweed and rose bengal sensitizer: influence of dye concentration. Int. J. Electrochem. Sci, 15 (2020) 3219-3231

[28] R.Xie, N. Ishijima, H. Sugime, and S. Noda, enhancing the photovoltaic performance of hybrid heterojunction solar cells by passivation of silicon surface via a simple 1-min annealing process, Scientific reports, 9 (2019) 1-7. https://doi.org/10.1038/s41598-019-48504-7

[29] G. Li, S. Shittu, T. M.O. Diallo, M. Yu, X. Zhao, and J. Ji, A review of solar photovoltaicthermoelectric hybrid system for electricity generation, Energy, 158 (2018) 41-58 https://doi.org/10.1016/j.energy.2018.06.021

[30] J. Meiss, C.L. Uhrich, K. Fehse, S. Pfuetzner, M.K. Riede, and K. Leo, transparent electrode materials for solar cells, The International Society for Optical Engineering, 7002 (2008) 1-10

[31] K., J.J. and S.Y. Foo, modeling of high-efficiency multi-junction polymer and hybrid solar cells to absorb infrared light, Polymers, 11 (2019) 1-16 https://doi.org/10.3390/polym11020383

[32] M.M.S. Sanad, A.E. Shalan, M.M. Rashad, and M.H.H. Mahmoud, plasmonic enhancement of low cost mesoporous $\mathrm{Fe}_{2} \mathrm{O}_{3}-\mathrm{TiO}_{2}$ loaded with palladium, platinum or silver for dye sensitized solar cells (DSSCs), applied surface science, 359 (2015) 315-322 https://doi.org/10.1016/j.apsusc.2015.10.106

[33] L. Kumar, V. Ragunathan, M. Chugh, and N. Bharadvaja, nanomaterials for remediation of contaminants: a review, Environmental Chemistry Letters, (2021) 1-23 https://doi.org/10.1007/s10311-021-01212-z 